\title{
A Method to Estimate Rain Rate over Tropical Oceans with the TRMM Microwave Imager Radiometer
}

\author{
C. PRABHAKARA \\ NASA/Goddard Space Flight Center, Greenbelt, Maryland, USA \\ R. IACOVAZZI, Jr. \\ Earth Resources Technology, Inc., Jessup, Maryland, USA \\ J.-M. YOO \\ EWHA Womans University, Seoul, South Korea \\ K.-M. KIM \\ University of Maryland Baltimore County, Baltimore, Maryland, USA \\ and \\ T. L. BELL \\ NASA/Goddard Space Flight Center, Greenbelt, Maryland, USA
}

(Manuscript received 6 November 2006, in final form 3 November 2007)

\begin{abstract}
In this preliminary study, we have developed a method to retrieve rain rate on a scale of $20 \mathrm{~km}$ from the brightness temperatures measured by the TRMM microwave imaging radiometer (TMI) over the tropical oceans, using the estimates of rain rate $\mathrm{R}_{\mathrm{PR}}$ made by the TRMM Precipitation Radar (PR) as a benchmark. The purpose of this study is to demonstrate with a limited amount of PR and TMI data the feasibility of improving the TRMM operational rain retrieval method V6 over the tropical oceans. This study utilizes the TMI-measured brightness temperatures $\mathrm{T}_{19 \mathrm{H}}, \mathrm{T}_{37 \mathrm{H}}$, and $\mathrm{T}_{85 \mathrm{H}}$ of horizontally polarized microwave radiances at 19,37 and $85 \mathrm{GHz}$, respectively, to deduce a salient non-linear parameter $\zeta$ that is highly correlated with $\mathrm{R}_{\mathrm{PR}}$ over the oceans. Two additional parameters generated from TMI data, $\omega$ and $\Gamma$, add significant amounts of rain information to our retrieval method. The parameter $\omega$ is based on $T_{19 \mathrm{~V}}$ and $\mathrm{T}_{21 \mathrm{~V}}$, the brightness temperatures measured by TMI for vertically polarized microwave radiances at 19 and $21 \mathrm{GHz}$ respectively. This parameter takes advantage of the independent information contained in $T_{21 \mathrm{v}}$. The parameter $\Gamma$ depends on the average horizontal gradient of the TMI-measured $\mathrm{T}_{85 \mathrm{v}}$ (vertically-polarized $85 \mathrm{GHz}$ radiance) in a $20 \mathrm{~km}$ footprint.

Initially our TMI rain retrieval algorithm is tuned with the help of $\mathrm{R}_{\mathrm{PR}}$ for seven cases of $2^{\circ} \times 3^{\circ}$ area over tropical oceans. Then it is applied to 13 other independent tropical ocean cases. For these independent cases, the rain rate $R^{*}$ estimated from our method correlates better with $R_{P R}$ than the rain rate $R_{V 6}$ retrieved from the present TMI V6 operational retrieval method. On a $20 \mathrm{~km}$ scale, the correlation between $R_{P R}$ and $R^{*}$ is better by about $6 \%$ compared to that between $\mathrm{R}_{\mathrm{PR}}$ and $\mathrm{R}_{\mathrm{V} 6}$. The slope of the regression line between the rain rates $R_{P R}$ and $R_{V 6}$ is about 0.5 . With respect to $R_{P R}$, the rain rate $R_{V 6}$ retrieved from operational V6 method tends to underestimate high rain rates and overestimate low rain rates. The slope of the regression line between
\end{abstract}


$R_{P R}$ and the rain rate $R^{*}$ retrieved with our method is about 0.8 , another indication of the improvement of $R^{*}$ over $\mathrm{R}_{\mathrm{V} 6}$. In addition, the area average rain rate on a scale of $2^{\circ} \times 3^{\circ}$ deduced from our method agrees better with that of PR by about $7 \%$.

\section{Introduction}

The Tropical Rainfall Measuring Mission (TRMM) satellite (see Kummerow et al. 2000) has enabled us to probe into the nature of rain, which is highly variable in space and time. The active rain sensing device Precipitation Radar (PR) and the passive sensing Microwave Imaging Radiometer (TMI) that are on board the TRMM satellite complement one another in measuring the distribution of rain over the tropical land and oceans. PR has a $220 \mathrm{~km}$ cross-track scanning capability that gives limited area coverage, while TMI has a $760 \mathrm{~km}$ conical scanning capability that results in a much larger area coverage. On the other hand, rain rate deduced from $P R$ can serve as a bench mark to develop a TMI rain retrieval algorithm. We may note that estimation of rain rate from PR is subject to the assumed drop size distribution.

The PR operates with $13.9 \mathrm{GHz}$ frequency and has a field of view (fov) of $4.3 \mathrm{~km}$ at nadir. It measures the vertical profile of the reflectivity with a resolution of 250 meters. The vertical profile of the liquid hydrometeors below the freezing level and frozen hydrometeors above the freezing level could be deduced from this reflectivity profile. Near-surface rain rate is estimated utilizing the near surface reflectivity assuming a rain drop size distribution (see Iguchi et al. 2000). This drop size distribution is chosen according to the type of rain, i.e., convective or stratiform. The type of rain is determined by the presence of a bright band in the reflectivity and/or horizontal uniformity in the reflectivity.

The TMI on the other hand observes brightness temperatures, $\mathrm{T}_{\mathrm{b}}$ 's, at five frequencies -10 , $19,21,37,85 \mathrm{GHz}$ - and in $\mathrm{V}$ and $\mathrm{H}$ polarizations (except at $21 \mathrm{GHz}$ where only $\mathrm{V}$ polarization is available). The fov of TMI increases from about $5 \mathrm{~km}$ at $85 \mathrm{GHz}$ to about $40 \mathrm{~km}$ as the frequency decreases to $10 \mathrm{GHz}$. The multi-channel observa-

Corresponding author: C. Prabhakara, NASA/Goddard Space Flight Center, Code 613.2, Greenbelt, Maryland, USA

E-mail: RAMICP@MSN.COM

(C)2008, Meteorological Society of Japan tions of TMI are designed to help retrieve the vertical profile of the hydrometeors in the atmosphere and the rain rate near the surface. Despite the fact that TMI measured Tb's range over 10 to $85 \mathrm{GHz}$, the information content of these channels pertaining to the vertical distribution of hydrometeors is limited (see e.g., Prabhakara et al. 2002). Because of this limitation, discrimination of convective rain from stratiform rain from TMI observations is poor. This leads to significant errors in the estimation of rain rate.

Nesbitt et al. (2004) found that compared to the TMI, the PR estimates of rainfall, $\mathrm{R}_{\mathrm{PR}}$, agree better with that of rain gauges over the tropics. Based on this validation we will use PR observations as a guide to develop a TMI rain retrieval method applicable to the tropical oceanic regions in the present study. The purpose of this study is to demonstrate in principle the feasibility to improve the microwave radiometer rain retrieval with a limited amount of TMI and PR data.

\section{Parameters in the rain retrieval model for tropical oceans}

There are many variables that affect $\mathrm{T}_{\mathrm{b}}$ 's- sea surface temperature, sea surface wind, water vapor in the atmosphere, vertical temperature distribution, the rain rate in the form of convective and stratiform rain having varied mix of liquid, frozen and mixed phase particles in the vertical column. Furthermore these variables could be distributed inhomogeneously in the horizontal field of view of the radiometer. Some of these variables can be present jointly.

In Figs. 1a and 1b, based on the observations of TRMM radar and radiometer, scattered plots of $T_{19 H}$ vs $R_{P R}$, and $T_{85 H}$ vs $R_{P R}$ are shown. From these figures we find, because of the joint effect of several variables, the $T_{b}$ 's vary over a wide range even for small rain rate.

Radiative transfer calculations have been used extensively in the estimation of rain rate (e.g., Kummerow et al. 2001) over oceans. In such calculations all the variables including sea surface wind are varied over a wide range to simulate the observed $\mathrm{T}_{b}$ 's in all the radiometric channels. 

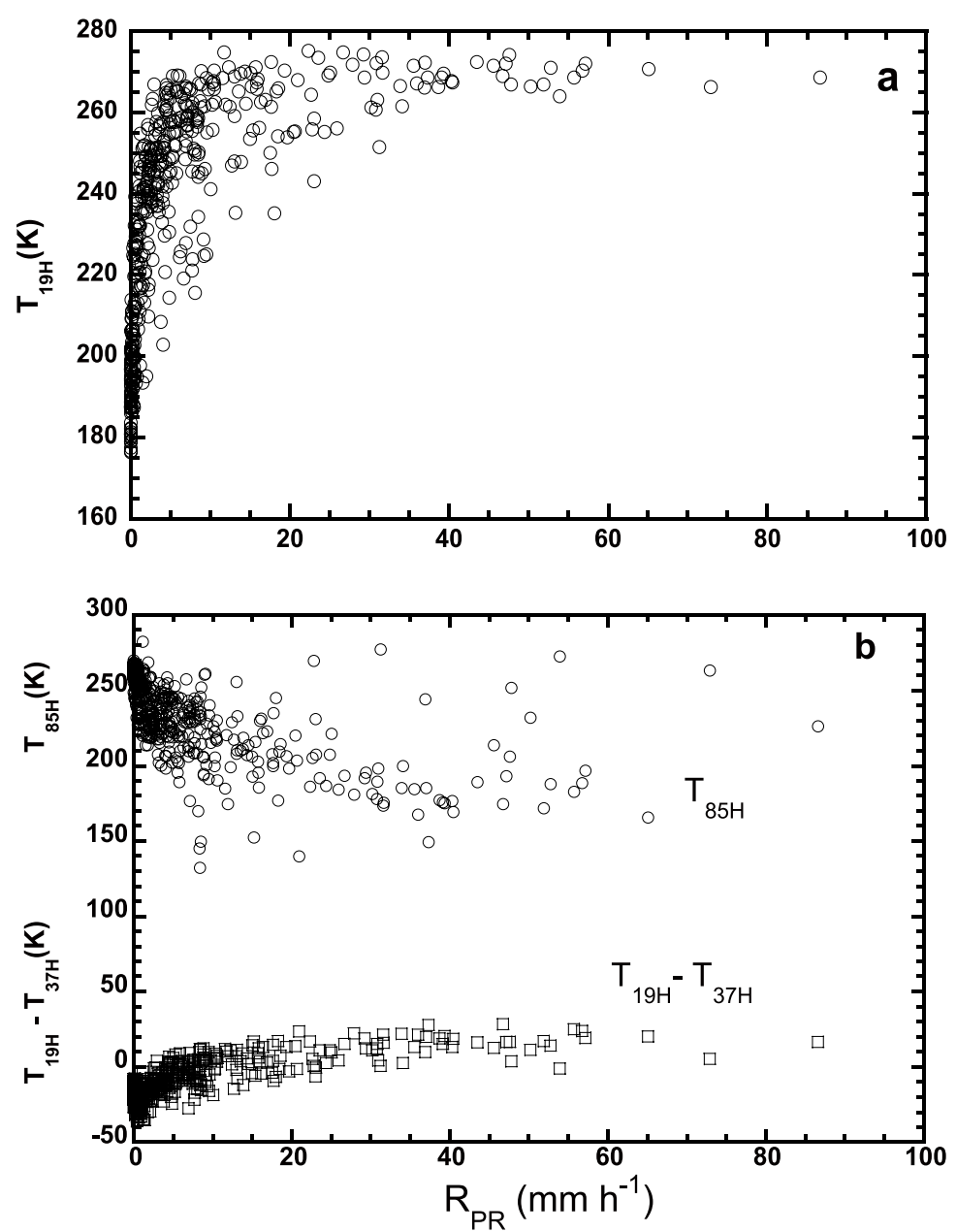

Fig. 1. Scattered plots of $R_{P R}$ vs. TMI measured $T_{b}$ 's on a scale of $20 \mathrm{~km}$ over ocean for December 19, 1997 (See Table 1).
a) $R_{P R}$ vs. $T_{19 H}$
b) $R_{\mathrm{PR}}$ vs. $T_{85 \mathrm{H}}$ and $\mathrm{R}_{\mathrm{PR}}$ vs. $\mathrm{T}_{19 \mathrm{H}}-\mathrm{T}_{37 \mathrm{H}}$.

Table 1. Dependent sample of TMI and PR data gathered from $2^{\circ} \times 3^{\circ}$ (Lat $\times$ Lon) areas of the tropical oceans. For this sample, correlation between $\mathrm{R}^{*}$ vs. $\mathrm{R}_{\mathrm{PR}}$, and $\mathrm{R}_{\mathrm{V} 6}$ vs. $\mathrm{R}_{\mathrm{PR}}\left(\mathrm{mm} \mathrm{h}^{-1}\right)$ on a scale of $20 \mathrm{~km}$ are shown. Also, the $2^{\circ} \times 3^{\circ}$ area average rain rates $\overline{R^{*}}, \overline{R_{V 6}}$, and $\overline{R_{P R}}\left(\mathrm{~mm} \mathrm{~h}^{-1}\right)$ are presented. The $2^{\circ} \times 3^{\circ}$ areas are identified with their central locations.

\begin{tabular}{|c|c|c|c|c|c|c|c|c|}
\hline \multirow[t]{2}{*}{ Day } & \multirow[t]{2}{*}{ Yr } & \multirow{2}{*}{\multicolumn{2}{|c|}{ Lat $\times$ Lon }} & \multicolumn{2}{|c|}{$\begin{array}{c}\text { Corr between } \mathrm{R}_{\mathrm{PR}} \\
\&\end{array}$} & \multicolumn{3}{|c|}{$\begin{array}{c}2^{\circ} \times 3^{\circ} \text { Area Average } \\
\left(\mathrm{mm} \mathrm{h}^{-1}\right)\end{array}$} \\
\hline & & & & $\mathrm{R}_{\mathrm{V} 6}$ & $\mathrm{R}^{*}$ & $\overline{R_{V 6}}$ & $\overline{R^{*}}$ & $\overline{R_{P R}}$ \\
\hline Dec 19 & 97 & $15.9^{\circ} \mathrm{N}$ & $136.4^{\circ} \mathrm{E}$ & 0.77 & 0.76 & 7.40 & 7.93 & 7.96 \\
\hline Jun 3 & 98 & $6.3^{\circ} \mathrm{N}$ & $13.0^{\circ} \mathrm{W}$ & 0.80 & 0.82 & 2.71 & 3.36 & 3.26 \\
\hline Jun 7 & 98 & $21.0^{\circ} \mathrm{N}$ & $118.2^{\circ} \mathrm{W}$ & 0.80 & 0.87 & 2.42 & 2.19 & 1.72 \\
\hline Jun 8 & 98 & $9.5^{\circ} \mathrm{S}$ & $85.0^{\circ} \mathrm{E}$ & 0.83 & 0.89 & 3.72 & 2.72 & 1.88 \\
\hline Jun 11 & 98 & $5.3^{\circ} \mathrm{N}$ & $93.7^{\circ} \mathrm{W}$ & 0.72 & 0.83 & 5.32 & 4.86 & 3.82 \\
\hline Jun 11 & 98 & $13.6^{\circ} \mathrm{N}$ & $105.2^{\circ} \mathrm{W}$ & 0.81 & 0.89 & 2.92 & 2.38 & 1.92 \\
\hline Jul 3 & 98 & $3.9^{\circ} \mathrm{N}$ & $91.9^{\circ} \mathrm{W}$ & 0.71 & 0.88 & 4.62 & 5.42 & 4.30 \\
\hline
\end{tabular}


Table 2. Independent sample of TMI and PR data gathered from $2^{\circ} \times 3^{\circ}$ (Lat $\times$ Lon) areas of the tropical oceans. For this sample, correlation between $\mathrm{R}^{*}$ vs. $\mathrm{R}_{\mathrm{PR}}$, and $\mathrm{R}_{\mathrm{V} 6}$ vs. $\mathrm{R}_{\mathrm{PR}}\left(\mathrm{mm} \mathrm{h}^{-1}\right)$ on a scale of $20 \mathrm{~km}$ are shown. Also, the $2^{\circ} \times 3^{\circ}$ area average rain rates $\overline{R^{*}}, \overline{R_{V 6}}$, and $\overline{R_{P R}}\left(\mathrm{~mm} \mathrm{~h}^{-1}\right)$ are presented. The $2^{\circ} \times 3^{\circ}$ areas are identified with their central locations.

\begin{tabular}{|c|c|c|c|c|c|c|c|c|}
\hline \multirow[t]{2}{*}{ Day } & \multirow[t]{2}{*}{$\mathrm{Yr}$} & \multirow{2}{*}{\multicolumn{2}{|c|}{ Lat $\times$ Lon }} & \multicolumn{2}{|c|}{$\begin{array}{c}\text { Corr between } \mathrm{R}_{\mathrm{PR}} \\
\&\end{array}$} & \multicolumn{3}{|c|}{$\begin{array}{c}2^{\circ} \times 3^{\circ} \text { Area Average } \\
\left(\mathrm{mm} \mathrm{h}^{-1}\right)\end{array}$} \\
\hline & & & & $\mathrm{R}_{\mathrm{V} 6}$ & $\mathrm{R}^{*}$ & $\overline{R_{V 6}}$ & $\overline{R^{*}}$ & $\overline{R_{P R}}$ \\
\hline Sep 1 & 98 & $26.1^{\circ} \mathrm{N}$ & $90.6^{\circ} \mathrm{W}$ & 0.83 & 0.83 & 4.00 & 3.72 & 2.68 \\
\hline Sep 26 & 98 & $8.5^{\circ} \mathrm{N}$ & $129.8^{\circ} \mathrm{W}$ & 0.81 & 0.90 & 2.55 & 2.42 & 1.99 \\
\hline Nov 10 & 98 & $5.5^{\circ} \mathrm{N}$ & $147.2^{\circ} \mathrm{E}$ & 0.76 & 0.85 & 5.26 & 6.60 & 6.41 \\
\hline Dec 1 & 98 & $1.0^{\circ} \mathrm{N}$ & $147.0^{\circ} \mathrm{E}$ & 0.78 & 0.91 & 1.75 & 1.65 & 1.24 \\
\hline Jan 7 & 99 & $4.5^{\circ} \mathrm{N}$ & $156.0^{\circ} \mathrm{E}$ & 0.78 & 0.86 & 3.13 & 3.52 & 2.90 \\
\hline Jan 24 & 99 & $6.0^{\circ} \mathrm{N}$ & $148.5^{\circ} \mathrm{E}$ & 0.71 & 0.79 & 7.58 & 7.91 & 5.82 \\
\hline Mar 4 & 99 & $0.4^{\circ} \mathrm{S}$ & $36.0^{\circ} \mathrm{W}$ & 0.71 & 0.81 & 3.55 & 3.64 & 2.87 \\
\hline Mar 6 & 99 & $14.4^{\circ} \mathrm{S}$ & $103.4^{\circ} \mathrm{E}$ & 0.83 & 0.91 & 5.61 & 5.93 & 4.80 \\
\hline Mar 9 & 99 & $27.0^{\circ} \mathrm{S}$ & $29.6^{\circ} \mathrm{W}$ & 0.80 & 0.88 & 3.86 & 2.98 & 2.54 \\
\hline Mar 11 & 99 & $25.2^{\circ} \mathrm{S}$ & $54.0^{\circ} \mathrm{E}$ & 0.75 & 0.82 & 2.30 & 3.10 & 1.94 \\
\hline Mar 14 & 99 & $25.9^{\circ} \mathrm{S}$ & $168.8^{\circ} \mathrm{E}$ & 0.83 & 0.89 & 2.11 & 1.80 & 1.43 \\
\hline Sep 13 & 99 & $24.0^{\circ} \mathrm{N}$ & $70.8^{\circ} \mathrm{W}$ & 0.51 & 0.72 & 7.22 & 8.18 & 8.01 \\
\hline Oct 16 & 99 & $18.1^{\circ} \mathrm{N}$ & $85.4^{\circ} \mathrm{E}$ & 0.53 & 0.75 & 5.22 & 7.19 & 6.69 \\
\hline
\end{tabular}

Then the set of computed $\mathrm{T}_{\mathrm{b}}$ 's in $19,37,85 \mathrm{GHz}$ that match closely observed $T_{b}$ 's is chosen to get the best estimate of rain rate. This method incorporates all the variables including the effect of wind speed. That method of rain rate estimation over oceans is adopted in the V6 official algorithm. The correlation of the V6 estimated rain rate over oceans with that observed by radar is about 0.74 (see Table 2). In our study the aim is to improve that correlation.

In developing suitable rain retrieval parameters based on TMI data over oceans, we are taking advantage of some insight gained from our earlier theoretical and observational studies (Prabhakara et al. 2002, 2005). These studies indicate that the difference in brightness temperature $\left(\mathrm{T}_{19 \mathrm{H}}-\mathrm{T}_{37 \mathrm{H}}\right)$ on land can be a valuable parameter in retrieving rain rate. (From hereafter for simplicity we will use the symbol $\mathrm{T}_{19 \mathrm{H}-37 \mathrm{H}}$ to represent $\mathrm{T}_{19 \mathrm{H}}-\mathrm{T}_{37 \mathrm{H}}$ ). Over the oceans, $\mathrm{T}_{19 \mathrm{H}-37 \mathrm{H}}$ is not as helpful because in the microwave region, surface emissivity over the oceans is significantly less than one and it increases with the microwave frequency (see, e.g., Chang and Wilheit 1979). Because of this reason a TMI rain retrieval method designed for land generally does not work well over oceans. Our aim is to retain the useful information given by the term $\mathrm{T}_{19 \mathrm{H}-37 \mathrm{H}}$ over the oceans with the help of some modifications.

\section{a. Parameter $\zeta$ based on 19, 37 and $85 \mathrm{GHz} T M I$ data}

The brightness values $\mathrm{T}_{19 \mathrm{H}-37 \mathrm{H}}$ and $\mathrm{T}_{85 \mathrm{H}}$ generally have a non-linear relationship with respect to the $P R$ derived rain rate $R_{P R}$. As an example, in Fig. 1b we are showing the non-linear relationship between $\mathrm{R}_{\mathrm{PR}}$ and $\mathrm{T}_{85 \mathrm{H}}$, and $\mathrm{R}_{\mathrm{PR}}$ and $\mathrm{T}_{19 \mathrm{H}-37 \mathrm{H}}$.

Over the oceans, the brightness values $T_{19 H-37 \mathrm{H}}$ and $\mathrm{T}_{85 \mathrm{H}}$ tend to behave in opposite fashion with respect to rain rate as shown in Fig. 1b. From this figure we see, $\mathrm{T}_{19 \mathrm{H}-37 \mathrm{H}}$ generally increases with rain rate when the rain rate exceeds a threshold of about $2 \mathrm{~mm} / \mathrm{h}^{-1}$, while $\mathrm{T}_{85 \mathrm{H}}$ tends to decrease with rain rate because of strong scattering. Furthermore the dynamic range of $\mathrm{T}_{19 \mathrm{H}-37 \mathrm{H}}$ is much smaller than that of $\mathrm{T}_{85 \mathrm{H}}$. Based on these observations we have formulated a nonlinear empirical parameter $\left[\left\{\left(69+\mathrm{T}_{19 \mathrm{H}-37 \mathrm{H}}\right)\right\}+\left\{\left(290-\mathrm{T}_{85 \mathrm{H}}\right) \times 0.2\right\}\right]^{2}$ with aim to improve the correlation with respect to $R_{P R}$. (see Fig. 2a). This nonlinear parameter is denoted by $\zeta$. Note $\mathrm{T}_{19 \mathrm{H}-37 \mathrm{H}}$ can be negative over ocean. So to keep the first term in $\zeta$ always positive over tropical oceans, a constant 69 is added. Recognizing that there is negative correlation between $\mathrm{T}_{19 \mathrm{H}-37 \mathrm{H}}$ and $\mathrm{T}_{85 \mathrm{H}}$ (see Fig. 1b), and $\mathrm{T}_{85 \mathrm{H}}$ does not exceed $290 \mathrm{~K}$ over tropical oceans, we have adopted $\left(290-\mathrm{T}_{85 \mathrm{H}}\right)$ as a suitable second term in formulating $\zeta$. Scaling $\left(290-\mathrm{T}_{85 \mathrm{H}}\right)$ by 0.2 in the second term is done to balance the significance of 

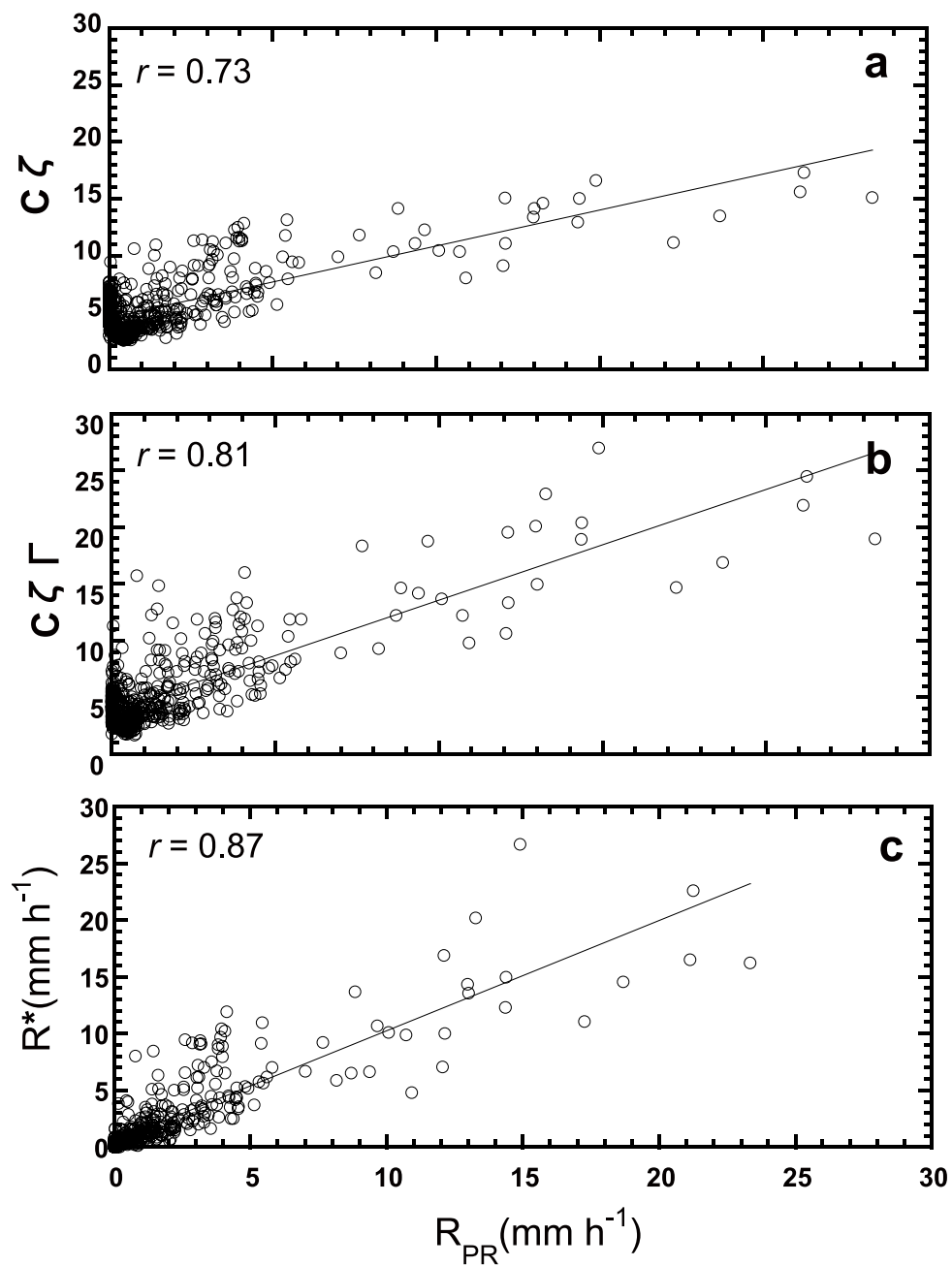

Fig. 2. Scattered plots of a) $R_{P R}$ vs. $C \zeta$, b) $R_{P R}$ vs. $C \zeta \Gamma$, and c) $R_{P R} v s$. $R^{*}$, deduced from the observations of TMI and Precipitation Radar on a scale of $20 \mathrm{~km}$ for June 3, 1998 (See Table 1).

the first and second terms in $\zeta$. We may note this one parameter $\zeta$ incorporates effectively the scattering and emission information about hydrometeors present in the TMI data at 19,37 and $85 \mathrm{GHz}$ over tropical oceans. This parameter $\zeta$ is deduced on a scale of $20 \mathrm{~km}$ which corresponds to the fov of $19 \mathrm{GHz}$ TMI channel. In addition to this key parameter $\zeta$ in our TMI method, to retrieve rain rate we have introduced two additional parameters that depend on TMI measurements.

\section{b. Parameter $\omega$}

The information contained in the $21 \mathrm{GHz}$ channel over the oceans differs significantly from that of $19 \mathrm{GHz}$ mainly because of water vapor absorption. From earlier studies (Chang and Wilheit
1979; Prabhakara et al. 1985), we know the combination $\left(\mathrm{T}_{21 \mathrm{~V}}-\mathrm{T}_{19 \mathrm{~V}}\right)$ reflects the water vapor content in the atmosphere over the oceans in the absence of rain. Furthermore, over the clear skies $T_{21 v}$ is greater than $T_{19 v}$. However, when there is rain, $T_{19 v}$ tends to be equal to $T_{21 v}$, i.e., $T_{19 \mathrm{~V}} \approx T_{21 \mathrm{v}}$. Based on this knowledge, we have formulated a parameter $\omega$ which is given by $\left\{1-\left(\mathrm{T}_{21 \mathrm{~V}}-\mathrm{T}_{19 \mathrm{~V}}\right) / 30\right\}$. This parameter tends to be close to 1 in the Inter-Tropical Coverage Zone (ITCZ) regions where there is aerially extensive and intense rain. However, it is much smaller than 1 over the subtropical oceans where there is subsidence and clear skies. This parameter $\omega$ is suitable for our rain retrieval. 

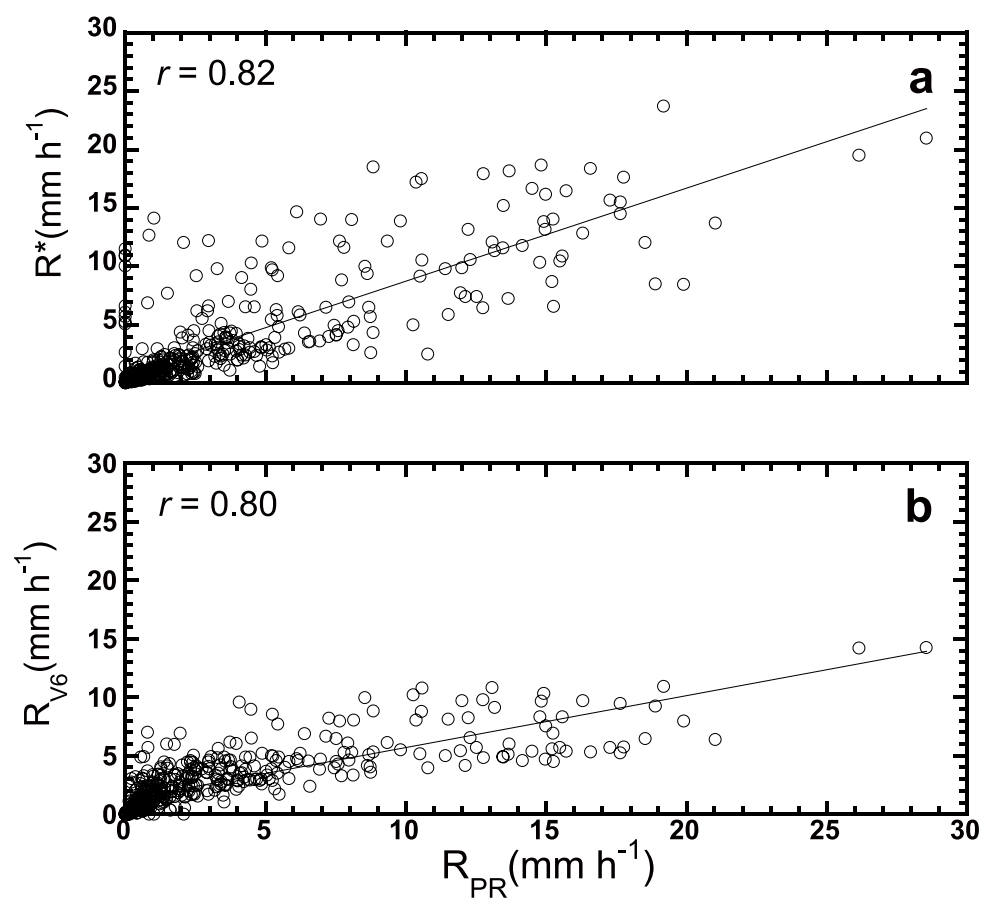

Fig. 3. a) Scattered plots of $R_{P R} v s . R^{*}$, and b) $R_{P R} v s . R_{V 6}$ for June 3, 1998 (See Table 1 ).

\section{c. Parameter $\Gamma$}

We find that when the average horizontal gradient $\left\langle\mathrm{dT}_{85 \mathrm{~V}} / \mathrm{dr}\right\rangle$, where $\mathrm{dr}$ is the distance between adjacent $\mathrm{T}_{85 \mathrm{~V}}$ data along a given swath, in a $20 \mathrm{~km}$ footprint of $19 \mathrm{GHz}$ channel is small, generally the rain rate is weak and it is of stratiform type. When this gradient is large, we infer there is relatively strong rain rate of convective type (Hong et al. 1999; Prabhakara et al. 2000). Using this reasoning, we have deduced empirically a nonlinear term $\left\langle\mathrm{dT}_{85 \mathrm{~V}} / \mathrm{dr}\right\rangle^{0.25}$ as a suitable parameter $\Gamma$ in our TMI rain retrieval model. However, gradient $\left\langle\mathrm{dT}_{85 \mathrm{~V}} / \mathrm{dr}\right\rangle$ fails to discriminate the convective/stratiform nature of rain in several situations. When the scale of convection is small and the updraft is not strong enough to produce sufficient dense ice particles aloft, $\left\langle\mathrm{dT}_{85 \mathrm{~V}} / \mathrm{dr}\right\rangle$ fails to detect the rain type.

\section{Rain retrieval formula applicable to tropical oceans}

With the help of the three parameters $\zeta, \omega$, and $\Gamma$ that have been discussed above, we have developed a nonlinear equation to estimate rain rate, $\mathrm{R}^{*}$, over oceans in our retrieval method.

$$
R^{*}=C \zeta \Gamma \omega
$$

Utilizing a dependent sample of TMI and PR data, the constant $\mathrm{C}=1.69 \times 10^{-3}$ is deduced by matching $R^{*}$ with the rain rate $R_{P R}$. The details pertaining to the time and location of the dependent sample of data taken by TMI and PR over an area of $2^{\circ} \times 3^{\circ}$ are shown in Table 1 . Also in the table we present the correlation between $R^{*}$ vs. $R_{P R}$ on a scale of $20 \mathrm{~km}$. The $2^{\circ} \times 3^{\circ}$ area-average rain rates $\overline{R^{*}}$ and $\overline{R_{P R}}$ are shown. The table also contains similar rain rate information, based on the operational TMI V6 method.

To demonstrate the relative importance of the parameters $\zeta, \omega$, and $\Gamma$ contained in Eq. (1), we show three plots in Figs. 2a, b and c. Figure 2a shows that $\mathrm{C} \zeta$ alone has a correlation of 0.73 with respect to radar rain rate $R_{P R}$. Then the product $\mathrm{C} \zeta \Gamma$ improves this correlation with respect to $\mathrm{R}_{\mathrm{PR}}$ to 0.81 as shown in Fig. 2b. Finally the product of $\mathrm{C} \zeta \Gamma \omega$, which is equal to our retrieved rain rate $\mathrm{R}^{*}$, has a correlation of 0.87 which is shown in Fig. 2c.

In order to illustrate the merits of the rain rate $\mathrm{R}^{*}$ retrieved from Eq. (1) on a scale of $20 \mathrm{~km}$ for one day, scattered plots of $R^{*} v s . R_{P R}$ are shown in Fig. $3 \mathrm{a}$ and in Fig. $3 \mathrm{~b}$ we show scattered plots of $R_{V 6}$ vs. $R_{P R}$. We notice from Figs. 3a and 3b that $\mathrm{R}_{\mathrm{V} 6}$ has a tendency to underestimate high rain rates and overestimate low rain rates. As a result, 


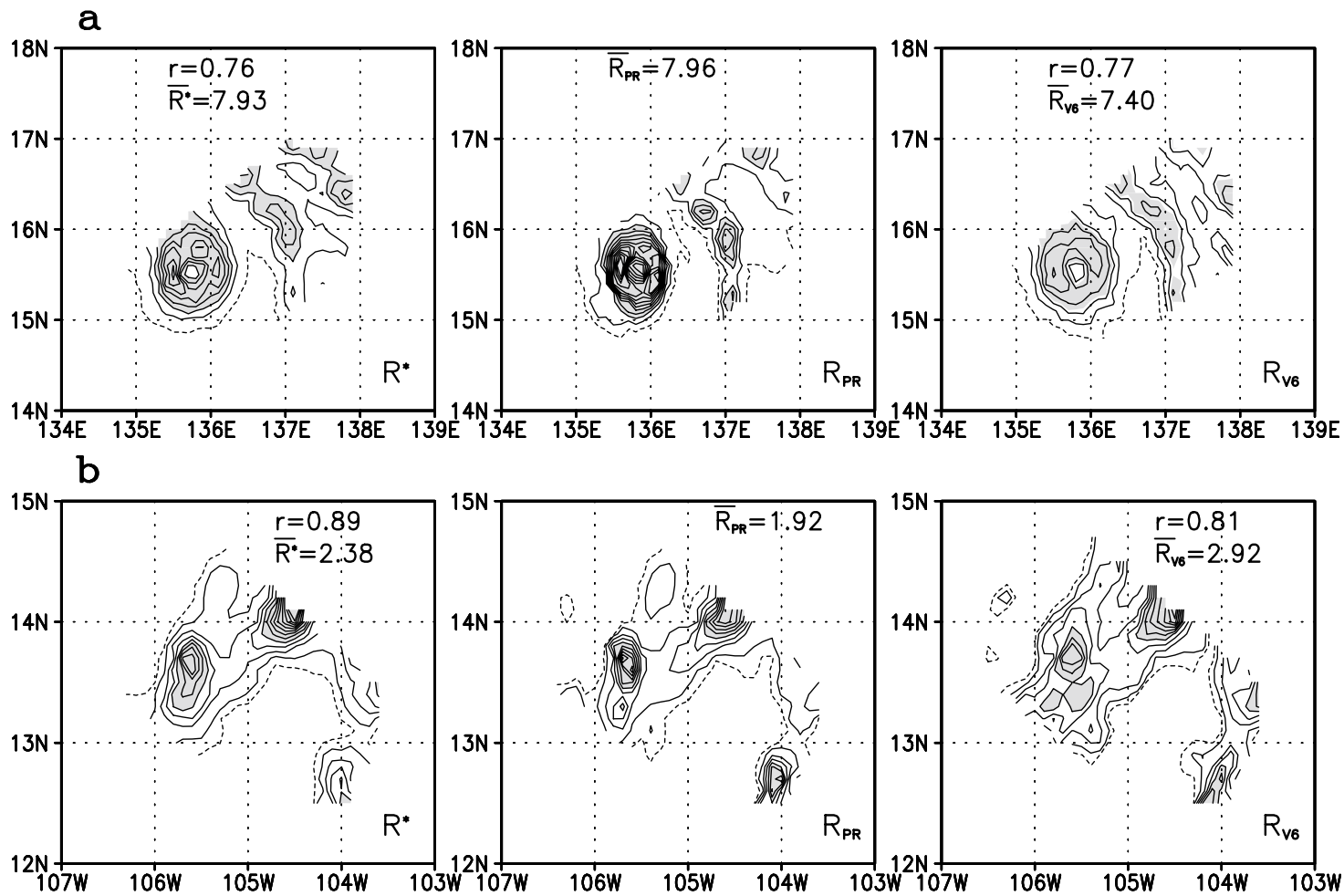

Fig. 4. a) Comparison of the maps of rain rate $R^{*}, R_{P R}$ and $R_{V 6}$ for a typhoon over Pacific Ocean on December 19, 1997 on a scale of $20 \mathrm{~km}$. A case from dependent sample. Contour interval is $5 \mathrm{~mm} \mathrm{~h}^{-1}$. Regions exceeding $10 \mathrm{~mm} \mathrm{~h}^{-1}$ are shaded. b) Same as a) except for June 11, 1998 over the Pacific Ocean on a scale of $20 \mathrm{~km}$. A case from dependent sample. Contour interval is $2 \mathrm{~mm} \mathrm{~h}^{-1}$. Regions exceeding $8 \mathrm{~mm}$ $\mathrm{h}^{-1}$ are shaded.

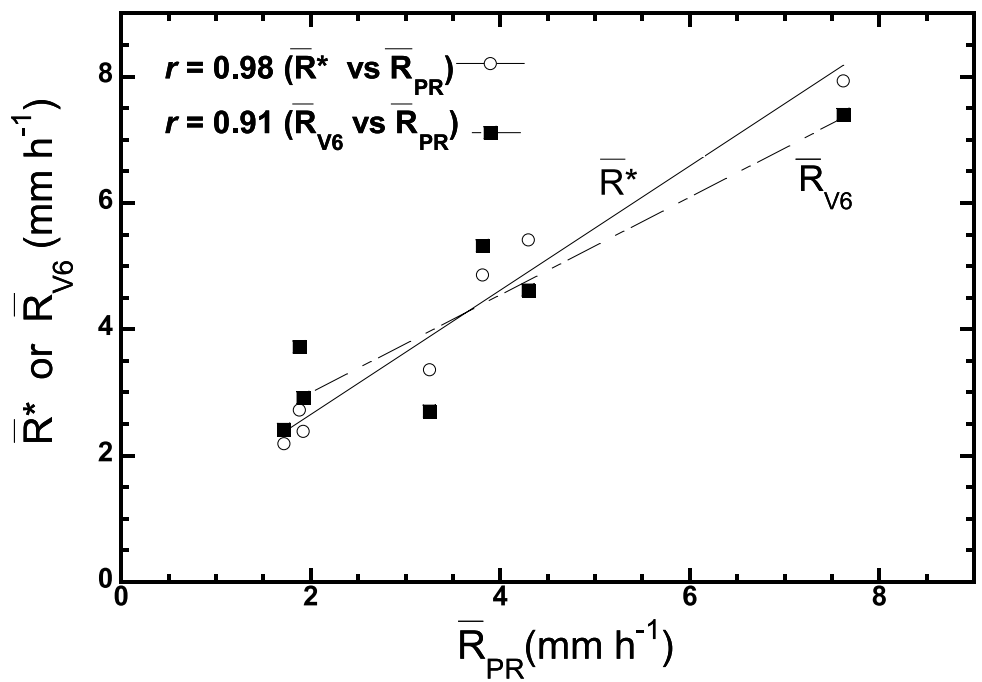

Fig. 5. Scattered plots of the $2^{\circ} \times 3^{\circ}$ area average rain rate $R^{*}$ and $R_{V 6}$ with $R_{P R}$ for the dependent sample. 


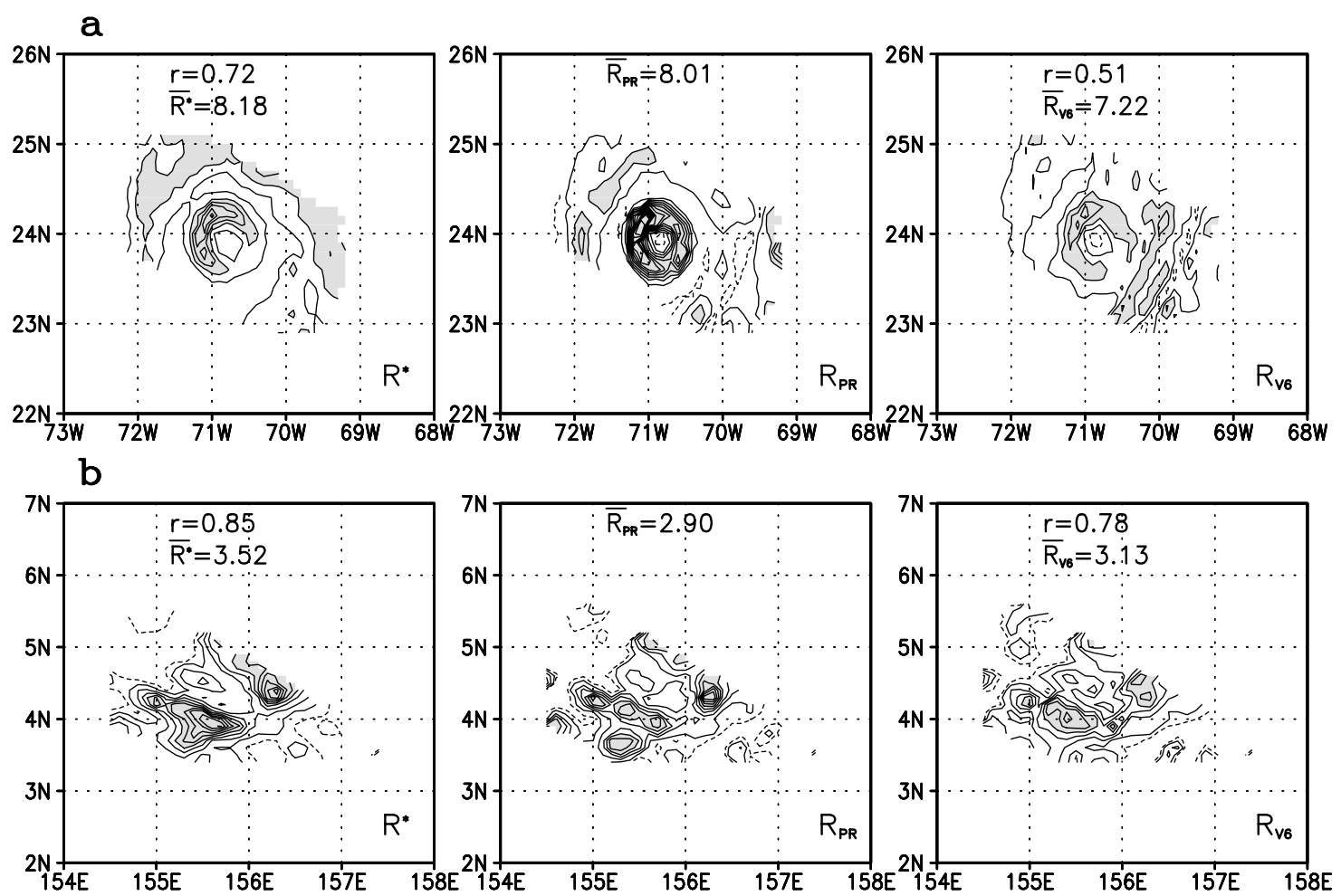

Fig. 6. a) Comparison of the maps of rain rate $R^{*}, R_{V 6}$ and $R_{P R}$ for Hurricane Floyd on September 13, 1999 on a scale of $20 \mathrm{~km}$. A case from independent sample. Contour interval is $5 \mathrm{~mm} \mathrm{~h}^{-1}$. Regions exceeding $10 \mathrm{~mm} \mathrm{~h}^{-1}$ are shaded. b) Comparison of the maps of rain rate $\mathrm{R}^{*}, \mathrm{R}_{\mathrm{PR}}$ and $\mathrm{R}_{\mathrm{V} 6}$ for the western equatorial Pacific Ocean on January 7, 1999 on a scale of $20 \mathrm{~km}$. A case from independent sample. Contour interval is $2 \mathrm{~mm} \mathrm{~h}^{-1}$. Regions exceeding $8 \mathrm{~mm} \mathrm{~h}^{-1}$ are shaded.

the slope of the regression line between $R_{P R}$ vs $R_{V 6}$ is 0.47 while that of $R_{P R}$ vs $R^{*}$ is 0.84 . This is a common shortcoming of $R_{V 6}$. Figures $4 a$ and $4 b$ allow us to compare the maps of rain rates $R^{*}, R_{P R}$ and $\mathrm{R}_{\mathrm{V} 6}$ for two days. The $2^{\circ} \times 3^{\circ}$ area averaged rain rates $\overline{R^{*}}$ and $\overline{R_{V 6}}$ are compared with $\overline{R_{P R}}$ in Fig. 5. From analysis of the dependent sample of TMI and PR data presented above, we show that our method of rain retrieval has the potential to perform better on $20 \mathrm{~km}$ and $2^{\circ} \times 3^{\circ}$ scales. However it is necessary to demonstrate the usefulness of our method from an independent sample of TMI and PR data.

\section{Results}

Having tuned our rain retrieval method with the dependent sample of rain events, we have applied Eq. (1) for thirteen independent cases listed in Table 2 to retrieve rain rate. In this table, the correlation between the averages, $R^{*}$ vs. $R_{P R}$ on a scale of $20 \mathrm{~km}$ is presented. Also the correlation between $\overline{R^{*}}$ and $\overline{R_{P R}}$ on a scale of $2^{\circ} \times 3^{\circ}$ is given. Similar information pertaining to $\overline{R_{V 6}}$ is also shown in the table. From Table 2, we note that the correlation between $R_{P R}$ vs. $R^{*}$ is significantly better than the correlation between $R_{P R}$ vs. $R_{V 6}$. We find in general $R_{V 6}$ tends to underestimate high rain rates as pointed out in the discussion of dependent cases. As a result, the slope of the regression line between $R_{P R}$ vs $R_{V 6}$ shown in Fig. 7 is typically $\sim 0.5$. That slope with respect to $R^{*}$ is $\sim 0.8$. The average rain rate $\overline{R^{*}}$ and $\overline{R_{V 6}}$ obtained from the independent samples are compared with $\overline{R_{P R}}$ in Fig. 7.

In Figs. $6 \mathrm{a}$ and $6 \mathrm{~b}$, maps of rain rates $\mathrm{R}^{*}, \mathrm{R}_{\mathrm{V} 6}$ and $R_{P R}$ derived on a $20 \mathrm{~km}$ scale are presented to reveal better agreement between $R^{*}$ and $R_{P R}$ for two independent cases. Also in the independent samples, the $2^{\circ} \times 3^{\circ}$ area-average rain rate $\overline{R^{*}}$ agrees better with respect to $\overline{R_{P R}}$. The correlation between $\overline{R^{*}}$ vs. $\overline{R_{P R}}$ is 0.97 while the correlation $\overline{R_{V 6}}$ vs. $\overline{R_{P R}}$ is 0.91 (see Fig. 7). 


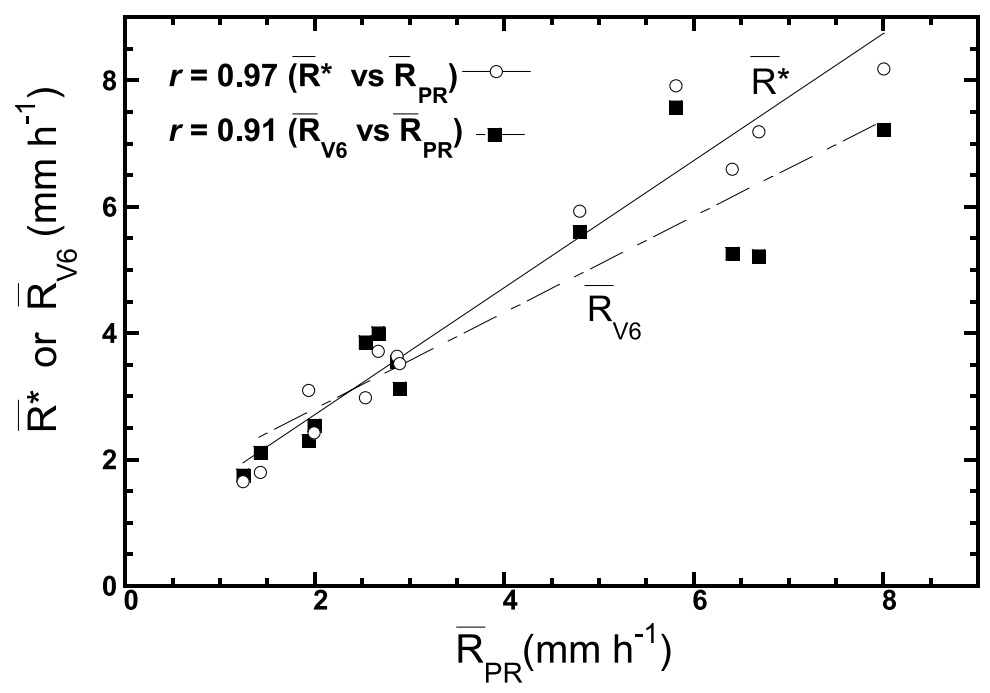

Fig. 7. Comparison of the $2^{\circ} \times 3^{\circ}$ area average rain rate $R^{*}$ and $R_{V 6}$ with $R_{P R}$ for the independent sample.

\section{Conclusions}

The retrieval of rain rate $R^{*}$ presented in this study implicitly hinges on several key physical elements-extinction of hydrometeors, water vapor in the atmosphere, and the non-uniformity in the fov. The physical basis of this method is fine tuned with the help of the $\mathrm{PR}$ rain rate. As a result agreement between $R^{*}$ and $R_{P R}$ can be significantly improved over widely different spatial scales.

As stated earlier, the operational rain retrieval method V6 is based on radiative transfer simulations of $\mathrm{T}_{\mathrm{b}}$ 's. Those simulations include the effects of sea surface wind and all the other variables. However, the correlation between rain rate $R_{\mathrm{V} 6}$ vs $R_{P R}$ is inferior by about 6\% compared to that given by $\mathrm{R}^{*}$ vs $\mathrm{R}_{\mathrm{PR}}$. The $2^{\circ} \times 3^{\circ}$ area average rain rate $\overline{R^{*}}$ agrees better with $\overline{R_{P R}}$ by about $7 \%$ compared to $\overline{R_{V 6}}$. These are improvements made by our retrieval method. These results indirectly suggest that explicit treatment of the surface wind effect is not needed to make improvement in our algorithm. The effect of the sea surface wind may be considered in future research investigations.

In the present retrieval method applicable to tropical ocean, we have not attempted to differentiate the intense rain rate associated with thunderstorm in developing stages from less intense rain rate associated with them in decaying stages (see Prabhakara et al. 2005). Finally we note TMI measurements at $10 \mathrm{GHz}$ are not used in our retrieval mainly because of the large foot print $(\sim 40 \mathrm{~km})$ in this channel. When the $10 \mathrm{GHz}$ measurements are available at a resolution comparable to that of $19 \mathrm{GHz}(\sim 20 \mathrm{~km})$, the information conveyed by them will be useful to enhance the rain retrieval.

\section{Acknowledgments}

During this research, Dr. Jung-Moon Yoo was supported by the Korean Research Foundation Grant (KRF-2005-041-C00477).

\section{References}

Chang, A.T.C. and T. Wilheit, 1979: Remote sensing of atmospheric water vapor, liquid water, and wind speed at the ocean surface by passive microwave techniques from the Nimbus 5 satellite. Radio Sci., 14(5), 793-802.

Hong, Y., C.D. Kummerow, and W.S. Olson, 1999: Separation of convective and stratiform precipitation using microwave brightness temperature. J. Appl. Meteor., 38, 1195-1213.

Iguchi, T., T. Kozu, R. Menegheni, J. Awaka, and K. Okamoto, 2000: Rain-profiling algorithm for the TRMM Precipitation Radar. J. Appl. Meteor., 39, 2038-2052.

Kummerow, C. and Coauthors, 2000: Status of the Tropical Rainfall Measuring Mission (TRMM) after two years in orbit. J. Appl. Meteor., 39, 1965 -1982 .

Kummerow, C., Y. Hong, W.S. Olson, S. Yang, R.F. Adler, J. McCollum, R. Ferraro, G. Petty, D.-B. Shin, and T.T. Wilheit, 2001: The evolution of the Goddard Profiling Algorithm (GPROF) for rainfall estimation from passive microwave sen- 
sors. J. Appl. Meteor., 40, 1801-1820.

Nesbitt, S.W., E.J. Zipser, and C.D. Kummerow, 2004: An examination of the version-5 rainfall estimates from the TRMM Microwave Imager, Precipitation Radar, and rain gauges on global regional, and storm scales. J. Appl. Meteor., 43, 1016-1036.

Prabhakara, C., D.A. Short, and B.E. Vollmer, 1985: El Niño and atmospheric water vapor: Observations from Nimbus 7 SMMR. J. Appl. Meteor., 24(12), 1311-1324.

Prabhakara, C., R. Iacovazzi, Jr., J.A. Weinman, and G. Dalu, 2000: A TRMM microwave radiometer rain rate estimation method with convective and stratiform discrimination. J. Meteor. Soc. Japan, 78, 241-258.

Prabhakara, C., R. Iacovazzi Jr., and J.-M. Yoo, 2002: TRMM Precipitation Radar and Microwave Imager observations of convective and stratiform rain over land and their theoretical implications. J. Meteor. Soc. Japan, 80, 1183-1197.

Prabhakara, C., R. Iacovazzi, Jr., J.-M. Yoo, and K.-M. Kim, 2005: A model for estimation of rain rate on tropical land from TRMM Microwave Imager radiometer observations. J. Meteor. Soc. Japan, 83, 595-609. 